\title{
DOPING GENÉTICO E POSSÍVEIS METODOLOGIAS DE DETECÇÃO
}

\author{
MS. ANDRÉ VALLE DE BAIRROS \\ Mestre em Bioquímica Toxicológica pela Universidade Federal de Santa Maria e Doutorando em \\ Toxicologia e Análises Toxicológicas da Universidade de São Paulo \\ (São Paulo - São Paulo - Brasil) \\ E-mail: andrebairros@yahoo.com.br
}

GRAD. ALEX ALMEIDA PREVEDELLO

Graduado em Farmácia pela Universidade Federal de Santa Maria (UFSM)

(Santa Maria - Rio Grande do Sul - Brasil)

E-mail: alex_prevedello@hotmail.com

ESP. LILIANA DE LOS SANTOS MORAES

Especialista em Farmácia Hospitalar pela Escola Superior de Gestão e

Ciências da Saúde, Farmacêutica da Secretária de Saúde do Município de Uruguaiana

(Uruguaiana - Rio Grande do Sul - Brasil)

E-mail: lili_moraes_4@hotmail.com

\begin{abstract}
RESUMO
O doping genético caracteriza-se pelo uso não terapêutico de células, genes e elementos gênicos, ou a modulação da expressão gênica com objetivo de aumentar o desempenho esportivo. Isto somente pode ser realizado através de manipulação gênica. Esta prática dopante caracteriza-se como virtualmente "indetectável", o que representa novos desafios analíticos para sua detecção. Esta revisão apresenta o doping genético e possíveis métodos de detecção para evitar futuras fraudes desportivas.
\end{abstract}

PALAVRAS-CHAVE: Atleta; detecção; doping; genes. 
A busca pelo ótimo desempenho tem sido uma constante no esporte de alto rendimento. Para tanto, muitos atletas acabam utilizando drogas e métodos ilícitos, que é denominado doping, os quais podem ter importantes efeitos adversos (ARTIOLI; HIRATA; LANCHA JÚNIOR, 2007). O doping está definido pela presença de substâncias proibidas (drogas ou fármacos que incrementam o rendimento de um atleta) e de seus metabólitos ou marcadores em uma amostra (sangue ou urina) de um atleta, além de métodos ilícitos (WORLD ANTI DOPING AGENCY, 20 I0). Entre as práticas proibidas pela WADA, encontra-se o doping genético.

O doping genético caracteriza-se pelo uso não terapêutico de células, genes e elementos gênicos, ou a modulação da expressão gênica, que tenham a capacidade de aumentar o desempenho esportivo (WORLD ANTI DOPING AGENCY, 20 I0). Tal prática é realizada por meio de manipulação gênica, que pode ser definida como um conjunto de técnicas que permitem a inserção e expressão de um gene terapêutico em células-alvo que apresentam algum tipo de desordem de origem genética (não necessariamente hereditária), possibilitando a correção dos produtos gênicos inadequados que causam doenças (HUARD et al., 2003).

Nesse sentido, os atletas poderiam beneficiar-se das técnicas de transferência de genes como qualquer outra pessoa cujo quadro clínico imponha tal necessidade (FILIPP, 2007). Além disso, a grande dificuldade de detecção desta prática dopante estimularia sua utilização em larga escala no meio esportivo (FILIPP, 2007). Entretanto, metodologias analíticas estão sendo desenvolvidas a fim de detectar alterações nos genomas de atletas e/ou seus respectivos produtos de biotransformação (ARGÜELLES; ZAMBORA, 2007; THEVIS et al., 20 I0).

Desta forma, o doping genético chama a atenção das autoridades quanto a sua incrível dificuldade para identificação deste método ilícito. Por isso, mais estudos são necessários para o desenvolvimento de metodologias analíticas capazes de detectar este tipo de fraude em exames antidoping.

\section{ASPECTOS GERAIS DO DOPING}

O conceito de dopagem apresentado no Código Antidopagem do Movimento Olímpico é "o uso de um expediente - substância ou método - que pode ser potencialmente prejudicial à saúde dos atletas, capaz de aumentar seu desempenho e que resulta na presença de uma substância proibida ou na evidência do uso de um método proibido no organismo do atleta" (RAMIREZ; RIBEIRO, 2005; OGA; CAMARGO; BATISTUZZO, 2008). 
Entre os fatores que contribuem para a dopagem estão: freqüência, duração e intensidade dos treinamentos e das competições; período de recuperação insuficiente entre os eventos; condições atmosféricas desfavoráveis e estresse provocado pelo público, meios de comunicação e patrocinadores (AQUINO NETO, 200 I; OGA; CAMARGO; BATISTUZZO, 2008).

A dopagem, além de ser um fato eticamente condenável, representa risco para quem a utiliza, pois a escolha da prática dopante é feita de acordo com o que o atleta, que hipoteticamente, acredita que poderá favorecer o seu rendimento em um determinado esporte. Por isso, a agência Mundial Antidoping (WADA) organiza uma lista com as classes de substâncias e métodos que apresentam como característica, pelo menos, dois dos três seguintes critérios: possibilidade de aumento no desempenho, risco à saúde e violação do espírito esportivo (OGA; CAMARGO; BATISTUZZO, 2008; DE ROSE, 2008).

Esta lista inclui agentes anabólicos, hormônios e outras substâncias relacionadas, agonista Beta-2 adrenérgico, agentes com atividade antiestrogênica, diuréticos e outros agentes mascarantes, estimulantes, narcóticos, canabinóides e glicocorticóides (WORLD ANTI DOPING AGENCY, 20 I0). De acordo com a WADA, o controle antidoping deve ocorrer durante o período das competições e entre os eventos esportivos. $O$ controle antidoping entre as competições pode ser feita a qualquer momento (no treinamento, na casa do atleta ou próximo a competição) e consiste na identificação e quantificação de agentes anabólicos e com atividade antiestrogênica, beta-2-agonista, diuréticos e agentes mascarantes (DE ROSE, 2008; WORLD ANTI DOPING AGENCY, 2009a). Em relação às metodologias analíticas empregadas no controle antidoping estabelecidas pela WADA, são divididas em 3 etapas: coleta da amostra, screening e confirmação do resultado (PEREIRA et al., 2008; WORLD ANTI DOPING AGENCY, 2009a).

Neste sentido, o controle do doping pode ser efetuado em amostra de urina, sangue ou ambos. Durante a coleta é verificado algum tipo de manipulação física ou química da amostra biológica (urina ou sangue). A amostra biológica passa por um screening que é realizado através de imunoensaio, eletroforese de focalização isoelétrica (eritropoetina sintética), cromatografia líquida (LC) e cromatografia gasosa (GC). Nos casos positivos, é refeito a mesma determinação para algumas substâncias como a eritropoetina recombinante humana (rEPO) e os ensaios cromatográficos são realizados novamente com auxílio de um espectrômetro de massa tandem $\left(M S^{n}\right)$. No caso de esteróides endógenos, os exames são realizados através de GC acoplado a um espectrômetro de massa de razão isotópica (GC-IRMS) (PEREIRA et al., 2008; WORLD ANTI DOPING AGENCY, 2009a). 
Recentemente, a WADA implementou o passaporte biológico, o primeiro método indireto que realiza uma série de coletas sanguíneas para verificação de alterações significativas em parâmetros desta amostra com o objetivo do monitoramento longitudinal em atletas de alto nível e que vem a somar-se aos tradicionais métodos diretos (WORLD ANTI DOPING AGENCY, 2009b). Em relação aos métodos proibidos pela WADA são enquadrados da seguinte maneira: transportadores de oxigênio, manipulações químicas e físicas e dopagem genética (WORLD ANTI DOPING AGENCY, 20I0).

\section{DOPING GENÉTICO}

doping genético é considerado o uso não terapêutico de células, genes e elementos gênicos que venha a aumentar o desempenho físico do atleta por meio da terapia gênica (WORLD ANTI DOPING AGENCY, 20 I0). A implicação das novas intervenções genéticas tem fascinado não só os pesquisadores, médicos e geneticistas, mas também treinadores e atletas que visam o aprimoramento do desempenho atlético de parâmetros biológicos, tais como força, potência e fornecimento de oxigênio, além do tratamento e reabilitação de lesões, para criar uma vantagem sobre os outros competidores (HUARD et al., 2003; HAISMA; DE HON, 2006; AZZAZY, 20I0).

Usando princípios básicos da terapia gênica, o doping genético injeta genes diretamente no corpo do atleta utilizando métodos in vivo ou ex vivo (AZZAZY; MANSOUR; CHRISTENSON, 2005). No método in vivo, a entrega do gene pode ser feita por métodos físicos, químicos ou biológicos, sendo este último o mais utilizado. Neste caso, utiliza-se vírus (retrovírus, adenovírus, vírus adeno-associados, lentivírus) como vetores que são modificados biologicamente para promover a inserção do gene artificial em células de um determinado órgão ou tecido-alvo (AZZAZY; MANSOUR; CHRISTENSON, 2005; SINN; SAUTER; MCCRAY JUNIOR, 2005). A técnica de doping genético ex vivo envolve a transferência, primeiramente, de genes para células em meio de cultura e reintrodução para o tecido alvo do atleta. Uma vez implantada no atleta, essas células aumentam a expressão de hormônios e outras substâncias bioquímicas que aumentam o seu desempenho físico (SINN; SAUTER; MCCRAY JUNIOR, 2005).

Os possíveis alvos primários do doping genético em humanos são: a eritropoietina (EPO), enzima conversora de angiotensina I, hormônio do crescimento humano $(\mathrm{hGH})$, fator de crescimento I semelhante a insulina (IGF- I), inibidor de genes da miostatina, folistatina, receptor ativado por proliferador peroxissomal (PPARs), fator de crescimento endotelial vascular (VEGF), endorfinas e encefalinas, 
leptina, fosfoenolpiruvato carboxiquinase (PEPCK) e actinina alfa-3 (ACTN3) (UNAL; UNAL, 2004; GATZIDOU; GATZIDOU; THEOCHARIS, 2009; AZZAZY, 20 I0). Diante da diversidade de genes, diferentes técnicas analíticas têm sido sugeridas para a determinação de doping genético.

\section{METODOLOGIAS PARA DETECÇÃO DO DOPING GENÉTICO}

A WADA iniciou uma série de pesquisas visando estar preparada para o mundo do doping genético (MCCRORY, 2003; PINCOCK, 2005). Os pesquisadores sugerem vários testes biológico-laboratoriais que podem expor fraudes genéticas (MCCRORY, 2003; PINCOCK, 2005; AZZAZY; MANSOUR; CHRISTENSON, 2005). Quando o perigo do doping genético foi reconhecido pela primeira vez, órgãos de controle de doping, cientistas e autoridades desportivas estavam preocupados com a dificuldade ou até mesmo incapacidade de sua detecção (FRIEDMANN; KOSS, 200I).

A base para essa opinião era que tanto o transgene quanto a proteína expressa seria indistinguível de seus homólogos endógenos (BAOUTINA et al., 2008). Neste sentido, Filipp (2007) discutiu a possibilidade de indivíduos que apresentam mutações benéficas em determinados genes alvos podem demonstrar vantagens naturais sobre os demais competidores, porém um exame antidoping baseado em uma análise genética poderia resultar em falso-positivo para o atleta com alguma mutação. Neste sentido, as estratégias analíticas para detecção do doping genético poderiam ser realizadas através da detecção direta e/ou indireta da manipulação gênica (AZZAZY; MANSOUR, 2007; PALMER et al., 2004).

\section{DETECÇÃO DIRETA DO DOPING GENÉTICO}

As estratégias adequadas que poderiam ser utilizadas para a detecção do doping genético seria a análise direta do transgene, da proteína transgênica e/ou do vetor utilizado para a introdução do transgene (AZZAZY; MANSOUR, 2007; BAUOTINA et al., 2008). Sugere-se a utilização de técnicas moleculares como a reação da transcriptase reversa, seguida da reação em cadeia da polimerase (RT-PCR) para o estudo de RNA, caso o problema seja a seleção da região do genoma para estudo. Os RNAs específicos codificam ou estão envolvidos na tradução de diferentes proteínas, sendo que por vezes, uma mesma proteína é traduzida por diferentes RNAs (WANG et al., 2003). 


\section{DETECÇÃO DE PROTEÍNAS TRANSGÊNICAS}

Na terapia gênica, transferência e subseqüente expressão do transgene são monitoradas pela detecção do produto do transgene ou por um componente do vetor. $\bigcirc$ transgene normalmente substitui um gene defeituoso, portanto há pouca expressão endógena dessa proteína. No doping genético, o transgene não visa substituir o gene defeituoso, e sim as proteínas recombinantes que são produzidas pelas próprias células dos atletas através do gene introduzido, tornando-as quase idênticas aos seus homólogos endógenos. Logo a detecção das proteínas transgênicas torna-se confiável na medida em que ocorrem mudanças nos níveis de expressão da proteína ou modificações pós-translacionais (PTM) quando o transgene é expresso ectopicamente (LASNE et al., 2002; BAOUTINA et al., 2008; AZZAZY, 20 I0).

Para a detecção do doping genético por meio da análise de proteínas alvos utilizando técnicas químicas padrões, mudanças nas concentrações de proteína ou isoformas precisariam ser evidentes em tecidos ou fluidos corporais de fácil acesso. Os estudos de terapia gênica em animais e humanos têm demonstrado que a expressão do transgene é geralmente confinada ao local/tecido onde é realizada a injeção/inserção do transgene. O tecido muscular é o principal alvo para essa prática, portanto para acompanhar a concentração da proteína, uma biopsia muscular seria exigida para revelar possíveis veículos virais ou alteração de genes (MCCRORY, 2003; PINCOCK, 2005), o que torna praticamente inviável no cenário atual do esporte (BAOUTINA et al., 2008).

As proteínas constituintes de hormônios como EPO e hGH quando secretadas, podem ocasionar algum "vazamento" para a circulação e possivelmente para a urina. Dessa forma, as proteínas transgênicas funcionais poderiam gerar alguma informação para sua detecção em caso de doping (BAOUTINA et al., 2008).

Neste sentido, o conhecimento das técnicas moleculares é capaz de diferenciar um genoma normal em relação a um alterado. $O$ desenvolvimento dos testes moleculares pode ser resumido nos seguintes passos: extração de moléculas de DNA ou RNA no sangue ou tecido objeto de estudo; amplificação mediante reação em cadeia da polimerase (PCR) ou transcrição reversa (RT); estudos das seqüências de interesses; marcadores, biosensores, entre um vasto leque de técnicas moleculares existentes (ARGÜELLES; ZAMBORA, 2007).

Uma possível metodologia para indicar o uso de doping genético é a análise de RNA e outras possíveis proteínas marcadoras por meio de métodos cromatográficos acoplados a espectrômetros de massa em soro ou plasma com a utilização de técnicas proteômicas (HAISMA; DE HON, 2006).

Além disso, a eritropoietina (EPO), produzida in vivo para transferência gênica, difere de sua contraparte fisiológica (LASNE et al., 2004). As diferenças isoelétricas 
entre as isoformas de EPO foram detectadas no soro de macacos antes e depois de injeção intramuscular do vetor vírus adeno-associado contendo homólogo de ácido desoxirribonucléico complementar (CDNA) para EPO. Embora as características estruturais responsáveis por esse comportamento isoelétrico distinto não tenham sido elucidadas, a expressão ectópica da proteína transgênica no tecido muscular, pode resultar em modificações pós-translacionais (PTM) diferentes ao da EPO endógena. Esta descoberta abriu perspectivas importantes para o controle antidoping envolvendo transferências de genes (LASNE et al., 2004).

Uma metodologia adotada para a análise de genes é a técnica de microarrays, capaz de medir quantitativamente a expressão de milhares de genes em diferentes tecidos em apenas um ensaio (ROSA; ROCHA; FURLAN, 2007). Neste sentido, este método poderia ser aplicado no doping genético, pois esta metodologia poderia detectar a expressão de genes extras ou alterados, resultantes do doping genético.

No entanto, os experimentos com microarrays ainda são consideravelmente caros e trabalhosos. Além disso, tais experimentos envolvem uma série de procedimentos laboratoriais, desde a extração de RNA, transcrição reversa e marcação fluorescente, até a hibridização final, os quais invariavelmente introduzem diferentes níveis de variação adicional aos dados. Desta maneira, a condução de ensaios com microarrays requer cuidadoso delineamento experimental e análise estatística dos dados (ROSA; ROCHA; FURLAN, 2007). Em conseqüência destes fatores, a logística de um laboratório de exames antidoping não seria capaz de atender a demanda de exames em grandes competições, o que atualmente impossibilita a realização desta técnica na rotina de laboratorial.

\section{DETECÇÃO DO VETOR}

As abordagens para detecção de vetores virais pode ser dirigida através da detecção de partículas virais, proteínas virais ou ácidos nucléicos incorporados. Entretanto, a análise direta do vetor depende de vários fatores como o vírus utilizado, o local onde ocorreu a transferência gênica e o método para detecção do agente (BAOUTINA et al., 2008). A reação da polimerase em cadeia (PCR) é predominante neste tipo de análise. Esses vetores, o tipo de amostra e suas metodologias de detecção estão apresentados no Quadro I. 
Quadro I - Vetores virais, rota de entrega, amostra e métodos de detecção

\begin{tabular}{|c|c|c|c|}
\hline Vetor & Rota de entrega & Amostra & Método de detecção \\
\hline Retrovírus & Intravenosa & PBMC & PCR \\
\hline Lentivírus & Intramuscular & $\begin{array}{l}\text { Músculo (local da in- } \\
\text { serção) }\end{array}$ & PCR \\
\hline Adenovírus & $\begin{array}{l}\text { Subcutânea } \\
\text { Intravascular }\end{array}$ & $\begin{array}{l}\text { Urina, fezes, } \\
\text { saliva, sangue, } \\
\text { local da injeção }\end{array}$ & $\begin{array}{l}\text { PCR e ensaio } \\
\text { de infecciosidade }\end{array}$ \\
\hline Vírus adeno- associado & $\begin{array}{l}\text { Intravascular } \\
\text { Intramuscular }\end{array}$ & $\begin{array}{l}\text { Sangue, soro, } \\
\text { urina, fezes, saliva, } \\
\text { músculo, sêmen, } \\
\text { PBMC }\end{array}$ & PCR \\
\hline
\end{tabular}

Legenda: PBMC: Células mononucleares de sangue periférico; PCR: Reação em cadeia da polimerase.

A detecção direta de agentes utilizados no doping genético, com bases nas tecnologias atuais, pode apresentar alguns desafios e/ou certas limitações. As principais desvantagens deste tipo de detecção é a região do genoma a ser estudada devido a existência de diferentes genes que codificam proteínas musculares; as proteínas relacionadas com funções respiratórias ou energéticas; as proteínas relacionadas a neurotransmissores cerebrais ou hormônios. Todas elas, de maneira particular ou em conjunto, podem incrementar o rendimento de um atleta. Nem sempre haverá mudanças no genoma com a expressão de um gene, mas sim no fragmento de DNA transcrito como RNA mensageiro, e portanto, em proteínas funcionais (ARGÜELLES; ZAMBORA, 2007).

Uma estratégia alternativa é a utilização de métodos indiretos, com base na medição dos efeitos do doping genéticos nas células, tecidos ou em todo o organismo (BAOUTINA et al., 2008). No caso de doping genético por EPO, a detecção de alterações secundárias hematológicas e bioquímicas, tais como, aumento na hemoglobina, na contagem de reticulócitos e hematócrito, pode sugerir o doping (RIVERA et al., 2005). Além disso, Varlet-Marie e colaboradores (2004) demonstraram mudanças no metabolismo do ferro e do RNA mensageiro utilizando a reação da polimerase em cadeia (PCR) em tempo real.

Contudo, as implicações legais para o atleta com resultado positivo para qualquer forma de doping sugerem que, sempre que possível, um método direto que identifique inequivocamente a prática ou agente dopante, que tem por base medir mudanças em células, tecidos ou em todo o corpo (BAOUTINA et al., 2008). 


\section{DETECÇÃO INDIRETA DO DOPING GENÉTICO}

Alternativamente, métodos indiretos de detecção poderiam detectar mudanças mensuráveis induzidas pelo gene dopante. Por exemplo, tem sido demonstrado que após a inserção e/ou expressão da respectiva proteína recombinante, pode ocorrer uma resposta imune específica (GAO et al., 2004; PALMER et al., 2004). Além disso, mudanças na transcrição, proteínas e metabólitos padrões após a introdução do transgene pode levar a marcadores substitutos, capazes de serem detectados por diferentes abordagens analíticas (AZZAZY; MANSOUR, 2007; BAOUTINA et al., 2008).

Entre outros efeitos biológicos do doping genético, respostas imunológicas frente ao veículo de entrega do gene podem ser avaliadas. Além disso, mudanças no nível de expressão de outras proteínas ou ruptura bioquímica celular em resposta a uma proteína transgênica também pode ser avaliada (BESSIS; GARCIA COZAR; BOISSIER, 2004; BAOUTINA et al., 2008).

\section{RESPOSTA IMUNE HUMORAL DE VETORES DE TERAPIA GÊNICA}

A administração de vetores virais pode induzir também resposta imune humoral. Ambos os fatores virais relatados, tais como o tipo de vetor, sorotipo, dose e via de administração e fatores relacionados ao hospedeiro, tais como a genética afetam a extensão da resposta imune humoral ao vetor (BAOUTINA et al., 2008). Em seres humanos, a administração de vetor adenovírus ou vírus adeno-associado (AAV) gerou aumento de anticorpos séricos após injeções intramuscular (MANNO et al., 2003), intratumoral (DUMMER et al., 2000; FREYTAG et al., 2002), intradermal (HARVEY et al., 1999) ou intra-arterial (artéria hepática) (MANNO et al., 2006) apesar de a maioria dos pacientes testados já apresentarem anticorpos pré-existentes ao capsídeo viral ao encontro natural com esses vírus (CHIRMULE et al., 1999).

A resposta imune humoral a infecção pelo vírus herpes simples é bem caracterizada (KOELLE; COREY, 2003). Há um aumento de anticorpos anti-HSV, apesar de que $50-80 \%$ dos seres humanos já possuam esses anticorpos com resultado natural de infecção (WAKIMOTO et al., 2003). Os vetores retrovirais também induzem resposta imune humoral como demonstrado em animais, através de injeção intravascular ou intramuscular (MCCORMACK; GONDA, 1997; MCCORMACK et al., 200 I ), e em humanos através de injeção intraperitoneal (TAIT et al., 1999). Ao contrário de muitos sorotipos de adenovírus e vírus adeno-associados, os retrovírus tipo C não são conhecidos por infectar seres humanos (MCCORMACK et al., 200 I), assim a imunidade preexistente ao capsídeo não é comum, embora a presença de anticorpos em seres humanos tem sido relatada (TAlT et al., 1999). 
Este conhecimento sobre os vetores virais e a respectiva resposta imune humoral decorrente da terapia gênica pode ser aplicado para uma possível forma de detecção para o doping genético. Diante disso, exames imunológicos que avaliam os anticorpos destes vetores poderiam ser utilizados ( $M l$ et al., 2005). Entretanto, o atleta pode estar naturalmente infectado com um determinado vírus como o AAV, que é largamente disseminado nos tecidos humanos (GAO et al., 2004). Com isso, haveria uma elevada concentração de anticorpos AAV na circulação e o resultado deste exame no intuito de revelar o uso de manipulação gênica para fins de doping poderia ser inconclusivo.

\section{UTILIZAÇÃO DE BIOSENSORES}

Acredita-se que os biosensores podem desempenhar um importante e valioso papel no controle do doping genético, provavelmente em conjunto com outras tecnologias de análise. Apesar disso, nenhum teste está aprovado pela WADA para detecção do doping genético, havendo vários projetos de pesquisa patrocinados pela WADA para o desenvolvimento de metodologias para detectar esta prática dopante (MINUNNI; SCARANO; MASCINI, 2008). Os biosensores podem ser classificados em duas classes: catalíticos e baseados na afinidade (ABB). Como exemplo pragmático de biosensor catalítico, temos o sensor de glicose, amplamente utilizado no controle da glicemia. Já os biosensores baseados na afinidade, são assim classificados devido à interação com a amostra, onde ocorre a formação de um complexo de afinidade na superfície do sensor (MINUNNI; SCARANO; MASCINI, 2008).

Os ABBs são capazes de produzir uma resposta seletiva, sensível e reprodutível de uma amostra em um tempo curto e, além disso, eles tornam desnecessários ou reduzem consideravelmente o pré-tratamento das amostras. Isto se deve a um cristal de quartzo com capacidade piezoelétrica extremamente sensível a variações de massa molecular. Diante disso, múltiplas interações podem ser detectadas simultaneamente, além de sequências específicas de DNA, proteínas recombinantes e anticorpos. Em relação a este último, AABs apresentou-se como melhor opção de exame em relação ao ELISA por ser mais específico (MINUNNI; SCARANO; MASCINI, 2008).

Em relação aos métodos, eles podem ser utilizados tanto para formas diretas como indiretas de detecção (TOMBELLI; MINUNNI; MASCIN, 2005). Em particular, ABBs foram aplicados para a detecção de analitos alvos, tais como IGF- I (GUIDI et al., 200 I) e VEGF (LI; LEE; CORN, 2007). Além disso, serve para analisar os efeitos induzidos por transgenes, como por exemplo, resposta imune humoral de vírus adeno-associado (AAV), vetores de terapia gênica (PALMER et al., 2004) ou EPO em terapia genética (GAO et al., 2004).

Diante das possibilidades de análises com diferentes metodologias analíticas, Thevis et al. (20 I 0) desenvolveram um método para detecção de dois metabólitos 
urinários do gene agonista do PPAR-delta GW 5 I 6 utilizando cromatografia líquida acoplada a um espectrômetro de massa tandem (LC-MSn $)$ e ressonância magnética nuclear (RMN). Este trabalho científico permitiu pela primeira vez detectar metabólitos de um gene alvo do doping genético em uma situação de manipulação gênica na urina, o que permite a análise antidoping sem a necessidade de procedimentos invasivos.

\section{CONSIDERAÇÕES FINAIS}

Nesta revisão procuramos demonstrar o doping genético e as metodologias analíticas disponíveis e suas limitações. Porém, recentemente identificaram-se metabólitos de um gene alvo na urina em uma situação de manipulação gênica, abrindo caminho para a determinação analítica de outros metabólitos de genes alvos do doping genético em uma rotina de exames antidoping.

No entanto, um aspecto pouco discutido na literatura são estudos referentes à interação entre genes manipulados e o uso de fármacos. Este fato poderia mascarar o uso do doping genético. Deste modo, determinados fármacos que não estão na lista de substâncias proibidas da WADA poderiam ser acrescentadas, aumentando o número da classe de medicamentos e análogos. Conseqüentemente, isso acarretaria em novos desafios analíticos para a detecção do doping.

Diante disso, o doping genético é muito recente e carece de mais estudos, pois novos genes serão alvos deste tipo de doping, o que implicará em novos riscos a saúde do atleta, bem como na criação de novas metodologias analíticas para evitar fraudes em competições esportivas de alto nível.

\section{Gene doping and possible detection methodologies}

ABSTRACT: Gene doping is characterized by non-therapeutic use of cells, genes and genetic elements, or modulation of gene expression with the aim to increase sports performance. This can only be accomplished through gene manipulation. This doping practice is characterized as virtually "undetectable", which represents new challenges for analytical detection. This review presents and possible gene doping detection methods to prevent future sports cheats. KEYWORDS: Athlete; detection; doping; genes.

\section{Dopaje genética y los posibles métodos de detección}

RESUMEN. El dopaje genética se caracteriza por el uso no terapéutico de células, genes y elementos genéticos o la modulación de la expresión génica con el objetivo de aumentar el rendimiento deportivo. Esto sólo puede lograrse gracias la manipulación genética. Esta práctica dopante se caracteriza por ser casi "imperceptible", lo que representa nuevos retos para la detección analítica. Esto presenta la revisión y posible dopaje gen métodos de detección para prevenir los futuros tramposos en el deportes. PALABRAS-CLAVE: Deportista; detección; dopaje; genes. 


\section{REFERÊNCIAS}

AQUINO NETO, F. R. O papel do atleta na sociedade e o controle de dopagem no esporte. Revista Brasileira de Medicina do Esporte, São Paulo, v. 7, n. 4, p. I38- | 48, jul./ago. 200 I.

ARGÜELLES, C. F; ZAMBORA, E. H. Dopage genético: Transferencia génica y su posible detéccion molecular. Gaceta Médica de México, México, v. I43, n. 2, p. I69- I72, 2007.

ARTIOLI, G. G.; HIRATA, R. D. C.; LANCHAJUNIOR, A. H. Terapia gênica, doping genético e esporte: fundamentação e implicações para o futuro. Revista Brasileira de Medicina do Esporte, Rio de Janeiro, v. 13, n. 5, p. 317e-321 e, set./out. 2007.

AZZAZY, H. M. E. Gene doping. In: THIENE, D.; HEMMERSBACH, P. (Ed.). Doping in sports: biomechanical principles, effects and analysis. Germany: Springer, 2010, p. 485-5I2.

;; MANSOUR, M. M. H. Rogue Athletes and recombinant DNA technology: challenges for doping control. Analyst, London, v. 132, n. 10, p. 95 I-957, oct. 2007.

.; CHRISTENSON, R. H. Doping in recombinant era: Strategies and counterstrategies. Clinical Biochemistry, Canadá, v. 38, n. I I, p. 959-965, nov. 2005.

Gene doping: of mice and men. Clinical Biochemistry, Canadá, v. 42, n.6, p. 435-44I, apr. 2009.

BAOUTINA, A. et al. Developing strategies for detection of gene doping. The Journal of Gene Medicine, Pymble, v. I0, n. I, p. 3-20, jan. 2008.

BESSIS, N.; GARCIA COZAR, F.J.; BOISSIER, M.C. Immune responses to gene therapy vectors: influence on vector function and effector mechanisms. Gene Theraphy, Philadelphia, v. II, n. I, SIO-SI7, out. 2004.

CHIRMULE, N. et al. Immune responses to adenovirus and adeno-associated vírus in humans. Gene Therapy, Philadelphia, v. 6, n. 9, p. 1574- I583, sep. 1999.

DE ROSE, E. Doping in athletes: an update. Clinics in Sports Medicine, Maryland, v. 27, n. I, p. 107-130, jan. 2008.

DUMMER, R. et al. Biological activity and safety of adenoviral vector-expressed wild-type p53 after intratumoral injection in melanoma and breast cancer patients with p53-overexpressing tumors. Cancer Gene Therapy, Zürich, v. 7, n.7, p. 1069- 1076, jul. 2000.

FILIPP, F. Is science killing the sport? gene therapy and its possible abuse in doping. European Molecular Biology Organization, Germany, v. 8, n. 5, p. 433-435, may 2007.

FREYTAG, S. O. et al. Phase I study of replication-competent adenovirus-mediated double suicide gene therapy for the treatment of locally recurrent prostate cancer. Cancer Research, Detroit, v. 62, n. 17, p. 4968-4976, sep. 2002. 
FRIEDMANN, T.; KOSS, J.O. Gene transfer and athletics: an impending problem. Molecular Therapy, La Jolla, v. 3, n. 6, p. 819-820, jun. 2001.

GAO, G. et al. Clades of adeno-associated viruses are widely disseminated in human tissues. Journal of Virology, Washington, v. 78, n. 12, p. 638I-6388, jun. 2004.

GATZIDOU, E.; GATZIDOU, G.; THEOCHARIS, S. Genetically transformed world records: A reality or in the sphere of fantasy? Medical Science Monitoring, Athens, v. I 5, n. 2, p. RA4 I-RA47, feb. 2009.

GUIDI, A. et al. Comparison of a conventional immunoassay (ELISA) with a surface plasmon resonance-based biosensor for IGF-I detection in cow's Milk. Biosensors and Bioelectronics, Pisa, v. 16, n. 9, p. 97।-977, dec. 2001.

HAISMA, H. J.; DE HON, O. Gene doping. International Journal of Sports Medicine, Groningen, v. 27, n. 4, p. 257-266, apr. 2006.

HARVEY, B. G. et al. Cellular immune response of healthy individuals to intradermal administration of an El-E3- adenovirus gene transfer vector. Human Gene Therapy, New York, v. 10, n. 17, p. 2823-2837, nov. 1999.

HUARD, J.; LI, Y.; PENG, H.; FU, F. Gene therapy and tissue engineering for sports medicine. Journal of Gene Medicine, Pittsburg, v. 5, n. 2, p. 93-108, feb. 2003.

KOELLE, D. M.; COREY, L. Recent progress in herpes simplex vírus immunobiology and vaccine research. Clinical Microbiology Reviews, Seattle, v. I6, n. I , p. 96-I I3, jan. 2003.

LASNE, F. et al. Detection of isoelectric profiles of erythropoietin in urine: differentiation of natural and administered recombinant hormones. Analytical Biochemistry, Châtenay-Malabry, v. 31 I, n. 2, p. |19-126, dec. 2002.

LASNE, F. et al. "Genetic doping" with erythropoietin cDNA in primate muscle is detectable. Molecular Therapy, Châtenay-Malabry, v. I0, n. 3, p. 409-4 I 0, sep. 2004.

LI, Y.; LEE H. J.; CORN, R. M. Detection of protein biomarkers using RNA aptamer microarrays and enzymatically amplified surface plasmon resonance imaging. Analytical Chemistry, Washington, v. 79, n. 3, p. 1082-1088, feb. 2007.

MANNO, C. S. et al. AAV-mediated factor IX gene transfer to skeletal muscle in patients with severe hemophilia B. Blood, New York, v. IO I , n. 8, p. 2963-2972, apr. 2003.

MANNO, C. S. et al. Successful transduction of liver in hemophilia by AAV-Factor IX and limitations imposed by the host immune response. Nature Medicine, New York, v. 12, n. 3, p. 342-347, mar. 2006.

MCCORMACK, M. P.; GONDA, T. J. Expression of activated mutants of the human interleukin-3/ interleukine-5/granulocyte-macrophage colony-stimulating factor receptor common beta subunit in primary hematopoietic cells induces factor-independent proliferation and differentiation. Blood, New York, v. 90, n. 4, p. |47| - | 48|, 1997. 
MCCORMACK, J. E. et al. Factors affecting long-term expression of a secreted transgene product after intravenous administration of a retroviral vector. Molecular Therapy, San Diego, v. 3, n.4, p. 516-525, apr. 200 I.

MCCRORY, P. Super athletes or gene cheats? British journal of sports medicine, Melbourne, v. 37, n. 3, p. 192-193, jun. 2003.

MI, J. et al. Isolation and characterization of an anti-recombinant erythropoietin single-chain antibody fragment using a phage display antibody library. Analytical and Bioanalytical Chemistry, Beijing, v. 383, n. 2, p. 218-223, sep. 2005.

MINUNNI, M.; SCARANO, S.; MASCINI, M. Affinity-based biosensors as promising tools for gene doping detection. Trends in Biotechnology, Sesto Fiorentino, v. 26, n. 5, p. 236-243, may. 2008.

OGA, S.; CAMARGO, M. M. A.; BATISTUZZO; J. A. O. "Dopagem nos esportes". In: YONAMINE, M. Fundamentos de toxicologia. 3. ed. São Paulo: Atheneu, 2008. p. 333-344.

PALMER, D. H. et al. Virus-directed enzyme prodrug therapy: intratumoral administration of a replicantion-deficient adenovirus encoding nitroreductase to patients with resectable liver cancer. Journal of Clinical Oncology, Birmingham, v. 22, n. 9, p. I 546- I 552, may. 2004.

PEREIRA, H. M. G. et al. Analytical and logistical improvements in doping-control analysis at the 2007 Pan-American games. Trends in Analytical Chemistry, Amsterdan, v. 27, n. 8, p. 648-656, sep. 2008.

PINCOCK, S. Feature: gene doping. Lancet, London, v. 366, n. I, p. SI 8-SI 9, dec. 2005.

RAMIREZ, A.; RIBEIRO, A. Doping genético e esporte. Revista Metropolitana de Ciências do Movimento Humano, São Paulo, v. 5, n. 2, p. 9-20, jun. 2005.

RIVERA, V. M. et al. Long-term pharmacologically regulated expression of Erythropoietin in primates following AAV-mediated gene transfer. Blood, Cambridge, v. I05, n.4, p. I4241 430, feb. 2005.

ROSA, G. J. M.; ROCHA, L. B.; FURLAN, L. R. Estudos de expressão gênica utilizando-se microarrays: delineamento, análise, e aplicações na pesquisa zootécnica. Revista Brasileira de Zootecnia, Viçosa, v. 36, n. 0, p. 185-209, jul. 2007.

SINN, P. L.; SAUTER, S. L.; MCCRAY JÚNIOR, P. B. Gene therapy progress and prospect: development of improved lentiviral and retroviral vectors--desing, biosafety, and production. Gene Therapy, lowa City, v. 12, n. 14, p. 1089-1098, jul. 2005.

TAIT, D. L. et al. Ovarian cancer BRCAI gene therapy: Phase I and II trial differences in immune response and vector stability. Clinical Cancer Research, Nashville, v. 5, n. 7, p. |708-|7|4, jul. 1999. 
THEVIS, M. et al. Characterization of two major urinary metabolites of the PPARdelta-agonist GW I 516 and implementation of the drug in routine doping controls. Analytical and Bioanalytical Chemistry, Cologne, v. 396, n. 7, 2479-2491, apr. 2010.

TOMBELLI, S.; MINUNNI, M.; MASCIN, M. Analytical applications of aptamers. Biosensors and Bioelectronics, Sesto Fiorentino, v. 20, n. 12, p. 2424-2443, jun. 2005

UNAL, M.; UNAL, D. O. Gene doping in sports. Sports Medicine, Istanbul, v. 34, n. 6, p. 357-362, 2004.

VARLET-MARIE, E. et al. Analysis of human reticulocyte genes reveals altered erythropoiesis: potencial use to detect recombinant human erythropoietin doping. Haematologica, Montpellier, v. 89, n. 8, p. 991-997, aug. 2004.

WANG, Y. X. et al. Peroxissome-proliferator-activated receptor delta activates fat metabolism to prevent obesity. Cell, La Jolla, v. II3, n. 2, p. I59-170, apr. 2003.

WAKIMOTO, $\mathrm{H}$. et al. Effects of innate immunity on herpes simplex vírus and its ability to kill tumor cells. Gene Therapy, Charlestown, v. I0, n. I I, p. 983-990, jun. 2003.

WORLD ANTI DOPING AGENCY. Technical documents. nov. 2009a. Disponível em: < http:// www.wada-ama.org/en/Science-Medicine/Anti-Doping-Laboratories/Technical-Documents/> Acesso em: 2 de abril 2010.

WORLD ANTI DOPING AGENCY. Athlete biological passport. dec. 2009b. Disponível em: <http://www.wada-ama.org/Documents/Science_Medicine/Athlete_Biological_Passport/ WADA_AthletePassport_OperatingGuidelines_FINAL_EN.pdf $>$ Acesso em: 10 de abril 2010.

WORLD ANTI DOPING AGENCY. Prohibited list 20 10. I jan. 20 I0. Disponível em: < http:// www.wada-ama.org/Documents/World_Anti-Doping_Program/WADP-Prohibited-list/ WADA_Prohibited_List_2010_EN.pdf $>$ Acesso em: 25 de março 2010.

Recebido: 01 maio 2010

Aprovado: 18 abr. 201 |

Endereço para correspondência:

André Valle de Bairros

Avenida Professor Lineu Prestes, 580, bloco 13B

Bairro Cidade Universitária

São Paulo-SP

CEP: 05508-900 